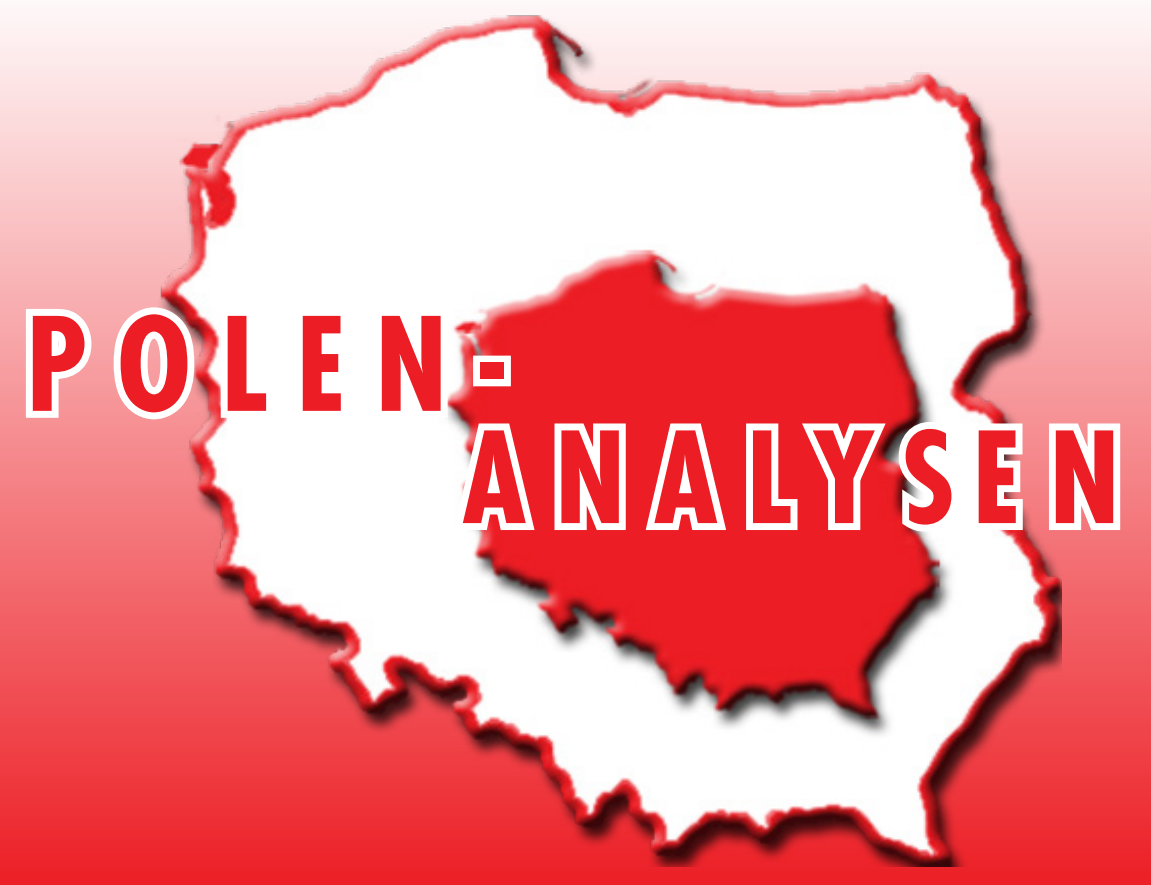

www.laender-analysen.de/polen

\title{
DAS VERHÄLTNIS ZWISCHEN KIRCHE UND STAAT UNTER DER PIS-REGIERUNG
}

\section{ANALYSE}

Das Verhältnis zwischen Kirche und Staat unter der PiS-Regierung

Theo Mechtenberg, Bad Oeynhausen

\section{DOKUMENTATION}

Ich klage an

Pater Ludwik Wiśniewski OP, Lublin

Erklärung der Polnischen Bischofskonferenz vom 17.01.2018 zum Artikel von Pater

Ludwik Wiśniewski unter dem Titel »Ich klage an«

CHRONIK

6. - 19. Februar 2018

\section{DEUTSCHES POLEN INSTITUT}

Forschungsstelle Osteuropa an der Universität Bremen
Deutsche Gesellschaft

für Osteuropakunde e.V. 


\title{
Das Verhältnis zwischen Kirche und Staat unter der PiS-Regierung
}

\author{
Theo Mechtenberg, Bad Oeynhausen
}

\section{Zusammenfassung}

Innerhalb von nur zwei Jahren zeigte sich im Verhältnis der katholischen Kirche Polens zur nationalkonservativen Regierung ein Wandel. Hatte sie fast geschlossen den Regierungswechsel im Herbst 2015 begrüßt, so machte sich nach einiger Zeit unter ranghohen Bischöfen eine gewisse Ernüchterung breit, verbunden mit einem Dissens auf einigen politischen Problemfeldern, am deutlichsten in der Flüchtlingsfrage. Dieser Wandel wird allerdings nicht von Priestern und Bischöfen mitvollzogen, die Pater Tadeusz Rydzyk und seinem Medienimperium nahestehen, so dass von einer für die Kirche gefährlichen inneren Spaltung gesprochen werden kann.

$\mathrm{U}$ $m$ das gegenwärtige Verhältnis der Kirche zum Staat unter der Regierung der Partei von Jarosław Kaczyński, Recht und Gerechtigkeit (Prawo i Sprawiedliwość - PiS), zu verstehen, reicht es nicht, bei ihrem Wahlsieg im Herbst 2015 anzusetzen. Vielmehr ist es erforderlich, die Endphase der von der Bürgerplattform (Platforma Obywatelska - PO) geführten Vorgängerregierung in den Blick zu nehmen. Diese war durch einen Kulturkampf bestimmt, mit dem die Kirche, von der oppositionellen PiS und dem Medienimperium von Pater Tadeusz Rydzyk massiv unterstützt, bestrebt war, Gesetze zu verhindern, die nach ihrer Auffassung Ehe und Familie bedrohten sowie die nationale Identität gefährdeten.

Als erstes entzündete sich der Streit an der Ratifizierung der sogenannten Istanbuler Konvention zur „Verhütung und Bekämpfung von Gewalt gegen Frauen und häuslicher Gewalt«, in der neben anderen Faktoren auch die Religion als mögliche Rechtfertigung von Gewalt gegen Frauen Erwähnung findet. Zielscheibe der kirchlichen Kampagne war Präsident Bronisław Komorowski, der gehindert werden sollte, mit seiner Unterschrift der Konvention Gesetzeskraft zu verleihen. Die Tageszeitung Nasz Dziennik titelte in großen Lettern "Die Pilatusversuchung des Präsidenten" und forderte die Leser zu einer Unterschriftenaktion auf. Der zum Kreis um Pater Rydzyk zählende Bischof Ignacy Dec richtete einen offenen Brief an das Staatsoberhaupt und erinnerte den katholischen Präsidenten daran, "Gott mehr zu gehorchen als den Menschen" (Apg 5,21). Statt ein solch schweres Geschütz aufzufahren, wäre die Kirche besser beraten gewesen, die Konvention angesichts der statistisch erfassten jährlich 90.000 betroffenen Frauen und einer weit höheren Dunkelziffer zu ihrer ureigenen Angelegenheit zu machen.

Mehr noch als diese Konvention bewegte die angebliche Bedrohung durch den Genderismus die Gemüter. Die Bischofskonferenz sah sich zu einem in allen Kirchen verlesenen Hirtenbrief veranlasst, der zwar zu Recht vor einem ideologischen Genderismus warnte, aber eine
Differenzierung zwischen ihm und den wissenschaftlichen Genderstudies vermissen ließ. Bald wurde Gender zu einem die Öffentlichkeit weitgehend bestimmenden Thema. Der Bischof von Kielce zog gar eine Analogie zu Herodes und seinem Kindermord. Dariusz Oko, Priester und Professor, beschwor in seinem Gender-Kreuzzug das Schreckgespenst einer die Kirche, Polen und die menschliche Zivilisation insgesamt zerstörenden Gender-Ideologie. Und wer sich, wie Dominikanerpatres, innerhalb der Kirche mit der Gender-Problematik sachlich befasste, sah sich einem von Rydzyks Medienimperium in Szene gesetzten Kesseltreiben ausgesetzt.

Mit gleicher Erbitterung wurde der Kampf gegen das Projekt eines Gesetzes zur »Heilung von Unfruchtbarkeit" geführt, das unter bestimmten Bedingungen die Invitro-Fertilisation erlaubt. Die Kirche beließ es nicht bei ihren bioethischen Einwänden, sondern drohte jedem, der dieses Gesetz unterstützt, mit dem Ausschluss vom Empfang der Kommunion.

\section{Die kirchenpolitische Situation nach dem Wahlsieg der PiS}

Als die PiS 2015 die Wahl des Präsidenten für sich entschied und nach den gewonnenen Parlamentswahlen die Regierung übernahm, wurde dies von manchem Kirchenvertreter geradezu enthusiastisch begrüßt. So etwa von Czesław Stanisław Bartnik, emeritierter Theologieprofessor, kirchlich einflussreich und Begründer einer spezifisch polnischen »Theologie der Nation «: »Mit einem Male erscheint hier ein Polen wie der Erzengel Michael mit Gott im Herzen, ein Verteidiger der Kirche, das Schwert gegen Satan gerichtet. [...] Es erwacht eine von Gott und dem Christentum inspirierte Kultur, der geniale polnische Geist gewinnt an Leben, ein Bewusstsein von Würde und Ehre erfüllt die Nation, die Freude der Gotteskindschaft verleiht den Menschen Flügel der Hoffnung zu einem zeitlichen und ewigen Leben. [...] Der Präsident und der Präses der siegreichen Partei gehen zur heiligen Kommunion. [...] Frau Ministerpräsidentin ist wie die wahre Polnische Mutter aus polnischen Epen.» 
Und unter Hinweis auf all jene, die den Regierungswechsel eher als Schock empfanden, fügte er hinzu: „Kaum zu glauben, dass dieses allerhöchste Gut von Menschen bösen Willens am allermeisten gehasst werden kann.»

Vor dem Hintergrund ihrer kulturkämpferischen Auseinandersetzung mit der Vorgängerregierung ist es verständlich, dass auch Polens Bischöfe den Regierungswechsel begrüßten. Entsprechend äußerte sich der Vorsitzende der Bischofskonferenz, Erzbischof Stanisław Gądecki: »In all den Jahrzehnten nach dem Krieg gab es keinen solchen Moment eines übereinstimmenden Denkens zwischen Staat und Kirche. Das ist ein Augenblick des Umbruchs. "Offenbar hatte Gądecki nicht bedacht, in welch eine schwierige Situation dieser Umbruch die Kirche bringen könnte angesichts der Machtkonstellation aufgrund des Bündnisses zwischen Jarosław Kaczyński und Pater Tadeusz Rydzyk. Nicht ohne Grund hatte der PiS-Präses unmittelbar nach den Wahlen Rydzyk persönlich gedankt und zum Ausdruck gebracht, dass ohne ihn dieses Ergebnis nicht zustande gekommen wäre. Und dieses Bündnis besteht bis heute als ein die Herrschaft der PiS sichernder Grundpfeiler.

In diesem Bündnis spielt Kaczyńskis von seinem Lehrer Stanisław Ehrlich stark beeinflusste Staatstheorie eine entscheidende Rolle. Nach ihr beruht die Legitimität der Macht nicht auf dem Recht, sondern muss im "politischen Willen" gesehen werden, repräsentiert und aktualisiert durch die Partei, im Einklang mit dem von Rydzyk vertretenen nationalen Katholizismus, der von Kaczyński geteilt wird.

Das Problem ist nicht neu. Es stand bereits in den 1990 er Jahren zur Diskussion, als die Kirche im Verein mit dem nationalkonservativen Flügel der Solidarność und unter Missachtung demokratischer Regeln den Versuch unternahm, Polen in ihrem Sinne politisch zu gestalten. Damals warnte der im Jahr 2000 verstorbene Priester Józef Tischner eindringlich vor der Gefahr einer "politischen Religion", durch welche die Ebenen von Religion und Politik miteinander vermischt werden. Dies sei dort der Fall, "wo der politische Gegner mit Hilfe religiöser Inhalte definiert wird, wo man unter Berufung auf Gott glaubt, im Besitz der absoluten Wahrheit zu sein, wo man den politischen Gegner in ihrem Namen diskriminiert und wo das Evangelium als Quelle eines politischen Kampfes benutzt wird."Wo solches Denken Fuß fasse, seien im politischen Raum ein Dialog, eine Kooperation und ein für den gesellschaftlichen Frieden so notwendiger Kompromiss nicht mehr möglich.

\section{Pater Rydzyk und die Macht seines Medienimperiums}

Es ist diese insbesondere für Pater Rydzyk und sein Medienimperium charakteristische Vermischung von
Religion und Politik, durch welche die Religion politisiert und die Politik sakralisiert wird, die sich für Polens Kirche als eine ernste Bedrohung erweist: Radio Maryja erhebt den Anspruch, die Stimme der Kirche zu sein, die in jedem katholischen Haus Gehör finden soll. Zwar werden Gottesdienste und der täglich gebetete Rosenkranz ausgestrahlt, doch dann ergreift einer der zur PiS zählenden Politiker das Wort und beschuldigt die Vorgängerregierung des Verrats an Polen, beschwört die Gefahr von Terrorakten und einer Islamisierung für den Fall, dass man den syrischen Kriegsflüchtlingen Tür und Tor zum Land öffnet. Oder Direktor Rydzyk tritt selbst ans Mikrophon und verkündet seine Tiraden gegen alle imaginären Feinde Polens und der Kirche, gegen Kommunisten und Liberale, gegen Freimaurer und Linke, gegen die Europäische Union und die Berliner Regierung, die angeblich die nationale Identität der Polen und ihre Unabhängigkeit bedrohen.

Wer von den Gläubigen sollte nicht glauben, dass Radio Maryja die Stimme der Kirche ist und jeder "wahre» Katholik für die Partei mit dem biblischen Begriffspaar »Recht und Gerechtigkeit« als Namen einzutreten hat, wenn jüngst die Einweihung einer neuen großräumigen, mit Steuergeldern finanzierten Kirche in Lodz (Łódź) das Bild der Geschlossenheit von Staat und Kirche bietet? Ein gutes Dutzend Bischöfe war vertreten. In den ersten Bänken saßen etliche Minister und PiS-Politiker. Grußworte von Präsident Andrzej Duda und Ministerpräsidentin Beata Szydło wurden verlesen. Natürlich hatte auch der an diesem Tag verhinderte Kaczyński einen Brief gesandt, in dem er der "Vorsehung« dafür dankt, dass »sie Pater Tadeusz Rydzyk auf den Weg unseres Lebens gestellt hat.« Die Predigt von Bischof Wiesław Mering glich einer Laudatio auf Pater Rydzyk, der es verstehe, "die Liebe zum Vaterland zu wecken«, der die wahre Geschichte Polens darzulegen wisse und die mit der Smolensker Tragödie verbundenen Lügen entlarve. Dass weder Erzbischof Gądecki noch der Primas Polens unter den Gästen zu sehen waren und auch kein Grußwort der Bischofskonferenz einging, ist zu wenig, um klarzustellen, dass Radio Maryja nicht die Stimme der Kirche ist.

Wie wirkungsvoll diese von Pater Rydzyk mit seinem Medienimperium verbreitete "politische Religion" ist, zeigt der Leserbrief einer Katholikin aus einer Provinzkleinstadt: Vier der fünf Kirchen stehen ganz unter dem Einfluss von Radio Maryja, des Fernsehsenders Trwam und der Zeitung Nasz Dziennik, die im Kirchenvorraum zum Kauf angeboten wird. PiS-Politiker werden eingeladen und können im sakralen Raum ihre Parolen verkünden. Wer es von den Gläubigen wagt, an Demonstrationen gegen die Rechtsbrüche der Regierung teilzunehmen, wird im Gottesdienst förmlich 
mabgekanzelt«. Bis in die Beichtstühle reicht der lange Arm von Pater Rydzyk. Man muss vor dem Beichtgitter damit rechnen, gefragt zu werden, welche Zeitungen und Zeitschriften man liest. Im Falle der liberalen Tageszeitung Gazeta Wyborcza erhält man eine Buße, für die Lektüre des katholischen Wochenmagazins Tygodnik Powszechny begnügt sich der Beichtvater mit einer bloßen Ermahnung.

Neben der Sakralisierung der Politik durch Radio Maryja, Trwam und Nasz Dziennik gibt es die Politisierung des Sakralen durch die PiS. So finden seit nunmehr über sieben Jahren am 10. eines jeden Monats in Warschau, aber auch in und anderen Städten, ein Religion mit Politik vermischendes Gedenken an den Absturz der Präsidentenmaschine über dem Flughafen von Smolensk im Jahr 2010 statt. Es ist ein Ritual der Profanierung: Am Beginn steht eine Eucharistiefeier mit einer Predigt ganz im Geiste nationalen Martyriums. Es folgt eine Prozession mit Priestern und einem Kreuzträger an der Spitze, mit Transparenten, auf denen die damaligen Ministerpräsidenten Donald Tusk und Wladimir Putin für die nationale Tragödie verantwortlich gemacht werden. Am Ende dieser religiös-politischen Gedenkfeier dann in der Nähe des Präsidentenpalastes die Abschlusskundgebung, auf der Kaczyński seinen Gegnern Hass unterstellt und sich damit selbst zum Hassprediger macht: „Es kommt die Zeit der Wahrheit, der vollen Wahrheit - und die bald. Und es kommt die große Niederlage derer, die hassen, die im Grunde Polen hassen. Denn darum geht es - sie hassen Polen. Aber Polen siegt."

Es fehlt nicht an Stimmen einzelner Priester, die diese Form "politischer Religion" verurteilen. Der Dominikanerpater Ludwik Wiśniewski hält sie für "schlimmer als Heidentum«. Und der ehemalige Generalsekretär der Bischofskonferenz, Bischof Tadeusz Pieronek, nennt sie "reine Politik«, und was man da zu hören bekomme, lasse einem »die Haare zu Berge stehen.«

Was dagegen fehlt, ist eine offizielle Erklärung der Kirchenleitung, mit der sie feststellt, dass derlei Veranstaltungen mit dem christlichen Glauben unvereinbar sind und nur zur Spaltung in Kirche und Gesellschaft beitragen.

Diese »Politisierung der Religion« dürfte es eigentlich nach kirchlichem Verständnis gar nicht geben. Die Pastoralkonstitution des Zweiten Vatikanums "Gaudium et spes« vermerkt ausdrücklich, dass »die Kirche in keiner Weise hinsichtlich ihrer Aufgabe und Zuständigkeit mit der politischen Gemeinschaft verwechselt werden darf noch an irgendein politisches System gebunden ist. [...] Die politische Gemeinschaft und die Kirche sind auf je ihrem Gebiet unabhängig und autonom." Erst unter die- ser Bedingung spricht sich das Konzil für ein "Zusammenwirken zum Wohle aller« aus. (Art. 76)

\section{Die Einstellung der Kirche zur Justizreform}

Den ersten Test für das Verhältnis von Kirche und Staat nach der Übernahme der Regierungsverantwortung durch die PiS bildete die Justizreform. Als mit der Personalunion von Justizminister und Generalstaatsanwalt der Grundstein für die Aufhebung der Gewaltenteilung gelegt wurde, schwiegen die Bischöfe. Als der Konflikt um das Verfassungsgericht entbrannte, meldeten sich zwar einige Bischöfe zu Wort. Doch diese kritisierten nicht den Rechtsbruch der PiS, sondern die »Schreihälse für Demokratie«, die gegen diesen Machtmissbrauch auf die Straße gingen. Der mit Radio Maryja eng verbundene Bischof Mering machte sich sogar zum Regierungssprecher, indem er sich in einen Brief an Martin Schulz, den Präsidenten des Europäischen Parlaments, gegen dessen Ermahnung, rechtsstaatliche Prinzipien einzuhalten, verwahrte und bedauerte, dass er den Mund nicht gehalten habe.

Als im Sejm die umstrittenen Gesetze zum Obersten Gericht und zum Landesjustizrat behandelt wurden und es wieder landesweit zu Protesten kam, meldeten sich endlich ranghohe Kirchenvertreter mit einer veränderten Tonlage zu Wort. Der Pressesprecher der Bischofskonferenz rief sämtliche politischen Gruppierungen zur Verständigung auf, und der Primas von Polen, Erzbischof Wojciech Polak, forderte "einen auf den Fundamenten des demokratischen Rechtsstaates basierenden Dialog«. Er mahnte, »die weitreichenden Folgen einer Reform nicht aus den Augen zu verlieren." Und als Präsident Duda die Gesetze mit seinem Veto blockierte, bedankte sich Erzbischof Gądecki in seiner Eigenschaft als Vorsitzender der Bischofskonferenz für diesen Schritt. In seinem Schreiben beruft er sich ausdrücklich auf die katholische Soziallehre, welche die Demokratie als politisches System besonders schätze, und betonte, dass "eine authentische Demokratie nur in einem Rechtsstaat möglich ist. « Der Warschauer Kardinal Kazimierz Nycz hielt ostentativ zum 100. Jahrestag der Gründung des Obersten Gerichts einen Jubiläumsgottesdienst, in dem er davor warnte, dessen Unabhängigkeit anzutasten.

Diese in der Sache zwar eindeutigen, doch jede direkte Kritik der Regierungspolitik vermeidenden Stellungnahmen blieben ohne Wirkung.

\section{Die deutliche und doch wirkungslose Absage an den Nationalismus}

Im Verlauf von gut zwei Jahren hat die Einstellung der Kirchenleitung zur nationalkonservativen Regierung einen Wandel erfahren. Hatte sie im Herbst 2015 den 
Wahlsieg der PiS noch freudig begrüßt, so stellte sich bald Ernüchterung ein, und je länger die Kaczyński-Partei die Regierungsgeschäfte leitet, desto mehr nehmen die Problemfelder zu, auf denen sich zwar kein Konflikt, wohl aber ein Dissens abzeichnet. So beobachten Polens Bischöfe mit Sorge den zunehmenden Nationalismus, der unter der jetzigen Regierung eine Neubelebung erfährt und Erinnerungen an die Nationaldemokratie der Zwischenkriegszeit weckt.

„Poland first!« - unter dieser Devise lässt sich die Rhetorik sowie die Innen- und Außenpolitik von Partei und Regierung zusammenfassen. Es ist daher kein Wunder, dass in Polen ein bedenkliches Anwachsen rechtsextremistischer Gruppierungen und Aktivitäten zu verzeichnen ist.

Wer das Eigene überhöht, neigt dazu, das Fremde herabzuwürdigen. Die Folge ist, dass sich der Blick auf die Wirklichkeit eintrübt, die Fähigkeit zur Toleranz und zum Dialog eingeschränkt wird, Kompromisse schwieriger, wenn nicht gar unmöglich werden. Wer das Eigene überhöht, steht in der Gefahr, das Fremde als feindlich zu empfinden, das es zu bekämpfen gilt. Aggressivität, Fremdenfeindlichkeit und Fremdenhass sind die Folge. All diese Phänomene lassen sich an der von der PiS verfolgten Politik festmachen und bestimmen mehr noch das Erscheinungsbild rechtsextremistischer Gruppen.

Die Bischofskonferenz hat auf diese Entwicklung reagiert. Am 28. April 2017 veröffentlichte sie ein Dokument mit dem Titel »Die christliche Gestalt des Patriotismus«. Der Text unterscheidet klar und deutlich zwischen Patriotismus und Nationalismus, und ebenso deutlich wird Letzterem eine Absage erteilt. Die Bischöfe sprechen sich für einen "gastfreundlichen Patriotismus" aus, zeigen sich über den "tiefgreifenden politischen Streit, der heute unser Vaterland spaltet«, besorgt, beklagen "die übermäßigen politischen Emotionen« und warnen vor einer »übermächtigen Politisierung des öffentlichen Lebens«. Ihre Äußerungen zur Geschichtspolitik verbinden sie mit der Warnung vor einer Instrumentalisierung des nationalen Gedächtnisses für politische Zwecke.

Es ist ein sehr akademisch formulierter Text, der im Abstrakten verbleibt, der die mit dem Verhältnis von Staat und Kirche gegebene nationale Problematik zugleich anspricht und verdeckt. So ist mit dem Hinweis auf einen "gastfreundlichen Patriotismus« sicher die Bereitschaft zur Aufnahme von Flüchtlingen gemeint, doch direkt gesagt wird dies nicht. Diese Unbestimmtheit der Aussagen gilt für das Dokument im Ganzen. So fühlten sich denn die Kaczyński-Partei und ihre Regierung in keiner Weise angesprochen, geschweige denn zu einer kritischen Überprüfung ihrer Politik veranlasst. Verschiedene nationalistische Gruppierungen begrüß- ten sogar das Dokument in einer gemeinsamen Stellungnahme und sahen in ihm eine Bestätigung ihrer Anschauungen und Aktivitäten, nachzulesen in dem nationalkatholischen Internetportal Prawy: »Mit Dankbarkeit nehmen wir das Dokument der Konferenz des Polnischen Episkopats entgegen, das sich in so eindeutiger Weise für den Patriotismus unter jedem Aspekt des sozialen Lebens ausspricht.»

\section{Die deutsch-polnische Versöhnung - ein politischer Irrweg?}

Von einer deutschfeindlichen Kampagne begleitet, versucht die nationalkonservative Regierung über die im Potsdamer Abkommen getroffene Regelung hinaus, Deutschland mehr als 70 Jahre nach Kriegsende für die Kriegsverwüstungen im Zweiten Weltkrieg haftbar zu machen. In diesem Zusammenhang wird die deutschpolnische Versöhnung als solche in Frage gestellt. So erklärte der PiS-Abgeordnete Arkadiusz Mularczyk (47) im Sejm: "Wir Polen wurden über viele Jahre mit den Phrasen einer polnisch-deutschen Versöhnung betrogen." Im nationalkonservativen Lager spricht man daher von "Versöhnungsideologie« sowie - im negativen Sinn - von "Versöhnungspolitik» der deutschen Regierung und aller polnischen Vorgängerregierungen der PiS. Das Gerede von »Versöhnung« sei - so Professor Stanisław Żerko vom Posener Westinstitut (Instytut Zachodni, Poznań) - »reine Heuchelei«, und die »ethische Rhetorik" diene allein dem Zweck, Reparationszahlungen zu vermeiden.

Von diesem Angriff auf die deutsch-polnische Versöhnung ist Polens Kirche direkt betroffen. Schließlich war es der Polnische Episkopat, der 1965 seine Versöhnungsbotschaft an die deutschen Bischöfe gerichtet hat, zum Dialog, auch über die »heißen Eisen«, einlud und dafür einen Kirchenkampf mit dem kommunistischen System zu bestehen hatte. Die neuerliche versöhnungsfeindliche Rhetorik der PiS zielt damit auch gegen diese Initiative der polnischen Bischöfe. Mit ihr machen die Kaczyński-Partei und ihre Regierung faktisch die Kirche für die aus der Versöhnungsbotschaft resultierende und für Polen - wie sie meinen - höchst schädliche »Versöhnungspolitik" mitverantwortlich.

Dieser Angriff auf die zum Kern christlichen Selbstverständnisses zählende Versöhnung konnte nicht unwidersprochen bleiben. Mit einem Appell wandten sich die zur zwischenkirchlichen Kontaktgruppe gehörenden polnischen Bischöfe an die Öffentlichkeit. In ihm heißt es einleitend: „Versöhnung ist ein Wort, das seit über einem Vierteljahrhundert die polnisch-deutschen Beziehungen bestimmt. Sie ist ein großer Wert, den zu gewinnen es gelungen ist und den wir dank der Bemühungen nicht allein von Politikern, sondern von zahl- 
reichen Menschen guten Willens beiderseits der Grenze aufrechterhalten. Allerdings sind wir uns bewusst, dass man ihn leicht durch unüberlegte Entscheidungen, aber auch durch leichtfertiges Reden verlieren kann.»

So begrüßenswert dieser Appell einiger weniger Bischöfe auch ist, kritisch bleibt anzumerken, dass die Aussagen sehr allgemein gehalten sind und die versöhnungsfeindliche Rhetorik der PiS nicht direkt angesprochen wird. Zudem wäre es wünschenswert gewesen, wenn die Bischofskonferenz mit ihrem moralischem Gewicht Stellung bezogen und zum Ausdruck gebracht hätte, dass die von Jarosław Kaczyński negativ titulierte "Versöhnungspolitik» keineswegs gegen die Interessen Polens verstieß; sie entsprach ihnen vielmehr, wie dies - mit Ausnahme seiner Partei - von allen polnischen Regierungen nach 1989 gesehen und stets bekräftigt wurde. Man mag sich fragen, welchen Geschichtsverlauf die deutsch-polnischen und die europäischen Beziehungen genommen hätten, wären sie nicht durch Versöhnung, sondern durch eine feindliche Narration bestimmt gewesen.

\section{Deutlicher Dissens in der Flüchtlingsfrage}

Bezeichnend ist folgender Vorgang: Der Posener Erzbischof und Vorsitzende der Bischofskonferenz Stanisław Gądecki nahm - zeitgleich mit dem Rosenkranzgebet an Polens Grenzen - an der Gebetswache »Sterben in Hoffnung« teil. Während an den Grenzen Hunderttausende um Frieden beteten, unter ihrem Friedensgebet aber zumeist die Abwehr einer drohenden Islamisierung verstanden, kamen zu der Gebetswache lediglich etwa 120 Gläubige zusammen, unter ihnen kaum ein Priester. Nachdem zahlreiche Namen der auf dem Weg nach Europa umgekommenen Flüchtlinge verlesen worden waren, nutzte Erzbischof Gądecki die Gelegenheit, sich klar und deutlich für die Aufnahme von Flüchtlingen auszusprechen. In der Flüchtlingsfrage gehe es "weder um das Interesse des Staates noch um die nationale Sicherheit, sondern einzig und allein um den Menschen."

Die Szene verdeutlicht das Dilemma, in dem sich Polens Kirche angesichts der Flüchtlingsfrage befindet. Während die Regierung sich nicht nur weigert, die von der EU-Kommission beschlossene Quote von 7.000 Flüchtlingen aufzunehmen, sondern es ablehnt, auch nur einen einzigen Flüchtling ins Land zu lassen, hat sich die Bischofskonferenz für die Errichtung eines "humanitäre Korridors« ausgesprochen, eine Forderung, die bei der Regierung auf taube Ohren stößt. Doch nicht nur das. Der Gegensatz zwischen der kleinen in Posen versammelten Gemeinde und den Massen an Gläubigen an Polens Grenzen, den Rosenkranz zur Abwehr einer angeblich drohenden Islamisierung in den Händen, zeigt, dass nicht der Episkopat, wohl aber die Machtkonstellation von PiS und Rydzyk die Deutungshoheit in der Flüchtlingsfrage besitzt. Dies bestätigt im Übrigen eine Befragung von Priesteramtskandidaten verschiedener Seminare. Danach stimmten nur 30 Prozent der Befragten der Bitte von Papst Franziskus zu, jede Pfarrei möge eine Familie aufnehmen. 72 Prozent meinten, dass Flüchtlinge eine Bedrohung der Sicherheit seien, und 50 Prozent sahen in ihnen eine Gefährdung der Gesundheit. 13 Prozent der Kleriker haben nichts gegen eine Beteiligung von Priestern an antiislamischen Manifestationen, und 44 Prozent sind der Auffassung, man solle den Islam in Polen verbieten. Dieses erschreckende Ergebnis erklärt sich teilweise aus der Tatsache, dass nach dieser Befragung 83 Prozent der Seminaristen ihre Informationen aus dem Medienimperium von Pater Rydzyk und anderen rechtsnationalen Publikationen beziehen, die durch ihre Aggressivität und Unterstützung einer nationalistischen Politik bekannt sind.

Wohl auch um in der Flüchtlingsfrage einen Mentalitätswandel herbeizuführen, forderte der Episkopat auf Anregung von Janina Ochojska, Gründerin und Leiterin der auch im Nahen Osten tätigen Polnischen Humanitären Aktion (Polska Akcja Humanitarna), die Priester aller Diözesen dazu auf, am 14. Januar, dem Migranten und Flüchtlingen gewidmeten Gebetstag, den sonntäglichen Gottesdienst in der Intention des Papstes zu feiern. In zahlreichen, doch längst nicht in allen Pfarreien kamen die Geistlichen dieser Forderung nach.

Ein solcher Mentalitätswechsel könnte, so offenbar die Befürchtung der Sejmabgeordneten Krystyna Pawłowicz, möglicherweise die Abwendung eines Großteils der Wählerschaft von der PiS zur Folge haben und ihre Wiederwahl in knapp zwei Jahren gefährden. Jedenfalls sah sie sich genötigt, unmittelbar nach dem 14. Januar an den Warschauer Kardinal Nycz in einer Verbalattacke voller Verdrehungen den Kardinal unter anderem zu bitten, "gegen uns Polen keine hartnäckige moralische Gewalt anzuwenden, und zwar unter Nutzung einer solchen Interpretation unseres Glaubens, dass wir entgegen dem klaren Gebot seiner Verteidigung, entgegen unserer instinkthaften Ablehnung und entgegen der berechtigten Angst um unser Leben und unsere Sicherheit Migranten und Flüchtlinge aus Afrika, Asien und dem Mittleren Osten in unser christliches Land lassen, ein Land, das sich gerade jetzt anschickt, sich gegen eine linke kulturelle Aggression zu verteidigen."

Doch ihre Befürchtung, die den Dissens in der Flüchtlingsfrage überdeutlich macht, dürfte unbegründet sein. Um einen wirklichen Einfluss auf die Flüchtlingspolitik der Regierung auszuüben, reichen bloße pastorale Initiativen nicht. Dazu müsste wohl von Polens Bischöfen die Grenze vom Dissens zum Konflikt überschritten werden und ein Hirtenbrief mit klaren Worten wie denen des 
Dominikaners Wiśniewski in allen Kirchen zur Verlesung kommen: »Im Namen der Sorge um das Wohl der Nation, um die Existenz der Kirche, um die Verteidigung unseres Glaubens vor einer Überflutung durch den Islam das

Über den Autor

Dr. Theo Mechtenberg ist Theologe und promovierter Germanist. Er war über viele Jahre Dozent am Gesamteuropäischen Studienwerk e. V., Vlotho, dessen Vorstandsvorsitzender er bis November 2016 war. Er ist Autor zahlreicher Zeitschriftenbeiträge und Buchpublikationen zum Thema Demokratie und katholische Kirche in Polen.

DOKUMENTATION

\section{Ich klage an}

Pater Ludwik Wiśniewski OP, Lublin

\section{In Polen stirbt das Christentum. Ausgerottet wird es von eifrigen Mitgliedern der Kirche. Die Bischöfe schweigen, leider}

Vor einigen Monaten habe ich einen Brief an fast einhundert polnische Bischöfe geschickt, in dem ich mich bemühte, die wichtigsten Aufgaben zu definieren, die vor der polnischen Kirche stehen (der Text des Briefes wurde im Tygodnik Powszechny Nr. 22/2017 veröffentlicht). Ich schrieb ihn in der Überzeugung, dass dies meine letzte Äußerung zur Situation in der polnischen Kirche ist. Inzwischen habe ich jedoch verstanden, dass sich das Drama erweitert hat.

Vor unseren Augen stirbt in Polen das Christentum. Und das ist nicht die Leistung der libertären Propaganda, der Bestrebungen der Freimaurerlogen oder internationaler Verschwörungen. Das Christentum rotten wir selbst aus, die Geistlichen und die eifrigsten Mitglieder der Kirche, mit eigenen Händen und auf eigenen Wunsch.

Immer mehr Menschen hören auf, sich mit der Kirche zu identifizieren. Das Statistische Institut der Katholischen Kirche (Instytut Statystyki Kościoła Katolickiego) verzeichnete unlängst den seit einigen Jahren höchsten Rückgang der Kirchgänger. Im Jahr 2016 sank der Anteil im Vergleich zu 2015 um über 3 Prozent und betrug 36,7 Prozent - das ist der niedrigste Wert in der Nachkriegsgeschichte Polens.

Was ist passiert? Wir haben in unsere Religiosität ein Element eingeführt, das sie sprengt: die Feindseligkeit. Mit ihr sind wir nicht nur infiziert, sondern wir haben uns an sie gewöhnt: Sie wurde bis zu einem gewissen Grad geradezu unser Erkennungszeichen. Und wo die Feindseligkeit ist, da hat der Hass ein Bürgerrecht - den Feind muss man schließlich vernichten. Man kann dann also Menschen anspucken, verspotten und treten, man kann sie grundlos der Niedertracht oder gar eines Verbrechens bezichtigen und sich gleichzeitig auf das Evangelium berufen und sich in das Gewand des Verteidigers der christlichen Werte und der Kirche kleiden, an Wallfahrten zum Hellen Berg [Jasna Góra, Częstochowa/Tschenstochau, d. Übers.] teilnehmen, die Hände gottesfürchtig zum Gebet falten und in den Medien ein ins Gebet versunkenes Gesicht zeigen.

Das ist aber nicht mehr das Christentum, sondern seine Parodie.

\section{Flüchtlings-Antikatechese}

Eine Illustration, wie sehr die Feindseligkeit in unser Denken einsickerte, ist die Beziehung zu Flüchtlingen und Migranten. Noch vor zehn Jahren waren 70 Prozent der Polen der Meinung, dass, da wir in anderen Ländern würdig aufgenommen wurden, als wir Flüchtlinge waren, auch wir denjenigen Gastfreundschaft entgegenbringen sollten, die vor der Grausamkeit des Krieges fliehen. Heute ist alles umgekehrt: 63 Prozent der Polen sind gegen die Aufnahme von Flüchtlingen. Dies ist das augenfällige Resultat einer aggressiven Antikatechese, betrieben von Politikern und leider unterstützt von vielen Geistlichen.

Niemand sagt, dass es einfach ist, Neuankömmlinge zu beherbergen, insbesondere wenn sie einer anderen Kultur und Religion angehören. Aber jeder Mensch, dem Leid angetan und der verletzt wurde, auch der Flüchtling, hat, wie Papst Franziskus erinnert, das »Gesicht Christi«. Die Anhänger der Schließung der Grenzen gegenüber Fremden sagen, sie würden die christliche Zivilisation verteidigen, die religiöse Kultur, ja sogar das Evangelium und Christus selbst. "Der Mensch ist der Weg der Kirche«, lehrte uns jedoch unser heiliger Papst. Wir sollen dem Menschen dienen. Jedem. Dem anderen die Hand zu reichen, insbesondere dem Fremden, ist die beste Verteidigung Christi und der Kirche. 
Man mag nicht glauben, wie sehr die Feindseligkeit in die Köpfe der polnischen Katholiken Einzug gehalten hat. Vor einigen Tagen sagte ein mir nahestehender und verdienter Priester: »Zum Glück hat unsere Regierung die Barbaren nicht nach Polen hineingelassen. Das sind keine Menschen, das sind WILDE...«.

Die, die Polen heute regieren, sprachen die finstersten Ecken der polnischen Seele an. Es gelang ihnen, das "Ungeheuer zu formen" und fast zwei Drittel der Polen in Schrecken zu versetzen, und sie wussten genau, dass ihnen das einen Wahlerfolg würde bescheren können. Die Flüchtlinge aus Afrika und dem Nahen Osten, wurde den Menschen eingetrichtert, sind keine Opfer von Gewalt und Menschen, die um Hilfe rufen, sondern zynische Muslime, die die katholische Nation vernichten und polnische Frauen vergewaltigen werden.

Natürlich hat die Polnische Bischofskonferenz die Schaffung »humanitärer Korridore« vorgeschlagen. In anderen Ländern gibt es solche Korridore, sie belasten den staatlichen Haushalt nicht und ermöglichen die Behandlung von Patienten in kritischem Zustand, die in Syrien nicht auf Hilfe rechnen können. Aber unsere Regierung, zusammengesetzt aus Ministern, die bei den monatlichen Smolensk-Gedenkveranstaltungen [Gedenkveranstaltungen anlässlich des Flugzeugunglücks von Smolensk 2010, d. Übers.] in den ersten Reihen der Warschauer Kathedrale sitzen, lehnte diesen Vorschlag ab und behauptete, wenn ich recht verstanden habe, dass der Korridor eine Gefahr für die Sicherheit des Staates wäre. Eine größere Scheinheiligkeit kann man sich nicht vorstellen.

Man muss mit aller Kraft ausrufen: Die polnische Flüchtlingspolitik ist eine Schande. »An den Grenzen Europas, vor den Augen der zivilisierten Welt, kommen schutzlose Menschen ums Leben«, sagte Kardinal Kazimierz Nycz, und wir machen das Evangelium zunichte, wenn wir nicht unsere Hand ausstrecken. Bruderländer unserer europäischen Gemeinschaft, zum Beispiel Griechenland und Italien, mühen sich mit dem Problem der Flüchtlinge ab, die sie ja auch nicht zu sich eingeladen haben, aber Polen kündigt die Solidarität mit ihnen auf und isoliert sich immer mehr.

In einer solchen Situation hat jeder Schritt Bedeutung, so auch der Vorschlag von Janina Ochojska, den der Primas und die Vorsitzenden des Episkopats unterstützten, dass die Priester am 14. Januar, dem Welttag des Migranten und Flüchtlings, das Formular für die Messe für Flüchtlinge verwenden.

Aber viele Gläubige, die um die Kirche besorgt sind, wünschen, dass unsere Hirten den Regierenden erklären, dass sie das demokratische Recht der gewählten Vertreter der Nation anerkennen, Innen- und Außenpolitik zu betreiben, dass sie aber gleichzeitig als Hirten der Kirche verpflichtet sind, wauch politische Angelegenheiten einer sittlichen Beurteilung zu unterstellen, wenn die Grundrechte der menschlichen Person oder das Heil der Seelen es verlangen « (Gaudium et spes, 76). Daher erklären die Hirten der polnischen Kirche in aller Verantwortung, dass die Beziehung der Regierung zu den Flüchtlingen nicht dem Evangelium gemäß und nicht christlich ist. In diesem Zusammenhang bitten sie, dass die Verantwortlichen der Republik Polen ihre Politik nicht mit der Sorge um die christliche Religion und die katholische Kirche begründen. Nach der Bewertung der Bischöfe dient eine solche »Fürsorge« nicht der Kirche, sondern zerstört sie.

Allgemein verbreitet ist es, für die Hölle, die in Polen entfesselt wurde, einen Menschen verantwortlich zu machen. Auch ich habe bis zu einem gewissen Punkt so gedacht. Aber als im Sejm die schändlichen Worte »verräterische Fressen« und "Kanaillen« fielen und die Abgeordneten der Regierungspartei, anstatt vor Scham zu vergehen, diese Äußerungen noch mit stehenden Ovationen belohnten, habe ich verstanden, dass sie, die stehen und applaudieren, tatsächlich für das verantwortlich sind, was heute passiert.

Es ist noch nicht lange her, dass Polen ein geachteter Spitzenreiter der Veränderungen nach dem Zusammenbruch des Kommunismus war, doch nun ist es der "kranke Mann Europas". Seht Ihr das nicht, Ihr Abgeordneten und Senatoren? Viele äußerst ernstzunehmende Autoritäten klagen Euch der Zerstörung Polens an, ich aber, mit großer Verlegenheit, doch mit aller Entschiedenheit klage Euch der Zerstörung des Christentums an und bitte Euch deshalb, dass Ihr darauf verzichtet, zu erklären, dass Ihr die Verteidiger der Kirche seid.

\section{Die Vergiftung durch das Radio}

Die Gegner der Aufnahme von Flüchtlingen hätten nicht so großen Erfolg, wenn nicht seit Jahren Feindseligkeit in das religiöse Leben der Polen eingeträufelt worden wäre. Angesehene Psychologen bestätigen ja, dass es die beste, jedoch verurteilenswürdige Art und Weise ist, eine Gruppe zu integrieren, wenn man äußere Feinde erfindet und ständig damit Angst verbreitet. Ein Weltmeister in dieser Kategorie ist Pater Tadeuz Rydzyk [Direktor des nationalkatholischen Senders Radio Maryja mit Sitz in Thorn/Toruń, d. Übers.]. Zu seinen Auftritten gehören regelmäßig Sätze wie: Wir werden verfolgt, sie wollen uns vernichten, weil wir Polen und die Kirche lieben, sie greifen uns unaufhörlich an. Unsere Kritiker "gießen Hass auf die Polen, Polen, die Kirche und Radio Maryja«, sagt der Pater Direktor.

Gibt es im Radio Maryja, im Telewizja Trwam oder in der Tageszeitung Nasz Dziennik [nationalkatholische Medien, die von Rydzyk gegründet wurden, d. Übers.] kein Gebet? Doch. Gibt es keine hervorragenden Konferenzen und 
guten Texte? Doch. Warum werden sie dann von Wiśniewski und anderen angegriffen? Weil das Gebet von Angriffen auf Menschen durchsetzt ist, und das ist nicht mehr das Christentum.

Überall Feinde und Aggression zu sehen, sind spezifische Eigenschaften von Sekten. Prof. Norman Davies (wir haben seine Fähigkeit bewundert, ohne Emotionen auf die polnische Geschichte zu blicken und das in ihr zu sehen, was unsere eigenen Historiker nicht wahrnehmen) sagte kürzlich: "Die polnischen Gläubigen schlucken in den Kirchen Gift.«Diese Aussage lässt sich auch auf die Medien des Pater Direktors beziehen. Der Verfasser dieser Worte bemühte sich eine gewisse Zeit, den Rosenkranz im Radio Maryja zu beten, aber auf längere Sicht war es nicht möglich: Sogleich nach dem abschließenden »Amen« begann Herr Michalkiewicz oder ein anderer »verzückter Patriot», seine politischen Gegner zu bespucken, und sein größter Feind war immer die Vorgängerregierung, die »Polen ausplünderte, erniedrigte und an Berlin verkauft hat«.

Unlängst fand in Thorn wieder eine Feierveranstaltung des Radio Maryja statt. In Anwesenheit ganz intensiv ins Gebet versunkener Minister und Abgeordneter (Macierewicz, Ziobro, Szyszko, Błaszczak, Piotrowicz, Czarnecki) »kanonisierte« der Hauptzelebrant, Bischof Wiesław Mering, dem einige Dutzend andere Hierarchen assistierten, zunächst den Pater Direktor und wies anschließend auf die epochalen Verdienste seiner Werke hin („Wir danken für das Erwecken der Vaterlandsliebe, für die schwierige Kunst, diesem Vaterland zu dienen, dafür, seine wahre Geschichte darzustellen" sowie auch dafür, dass Radio Maryja standhaft alle Lügen über die Tragödie von Smolensk angeprangert hat und das Gewissen der Polen in diesem Bereich geweckt hat».). Die Feier wurde von Briefen des Präsidenten, der damaligen Ministerpräsidentin und vor allem des Präses von Recht und Gerechtigkeit (Prawo i Sprawiedliwość - PiS) gewürdigt. Jarosław Kaczyński, der vor einigen Jahren gesagt hatte, dass Pater Rydzyk den Interessen Russlands diene, schrieb: "Die Vorsehung stellte Pater Tadeusz Rydzyk auf den Weg unseres Lebens."

Auch dies muss mit lauter Stimme gesagt werden: Radio Maryja, Telewizja Trwam und Nasz Dziennik träufeln seit Jahren Gift ein und nennen das Evangelisierung. Dieses Gift ist umso giftiger, als viele Bischöfe seine Verbreitung unterstützen. Nur der schmerzlich vermisste Erzbischof Józef Życiński hatte den Mut, öffentlich zu sagen, dass diese Werke weit vom Christentum entfernt sind und die Menschen aus der Kirche treiben. Ich bin davon überzeugt, dass viele Bischöfe den Standpunkt von Erzbischof Życiński teilen, aber schweigen. Es schweigen dagegen nicht die Bischöfe, die nach Thorn fahren und den "großen Evangelisator der Nation" preisen, sowie die, die an die Redaktion des Nasz Dziennik Grüße zu den Feiertagen schicken und damit dem Tun Pater Rydzyks Glaubwürdigkeit verleihen.

Ich habe mich zu diesen Worten entschlossen, weil ich die Traurigkeit, den Schmerz und sogar den Wunsch, aus der Kirche auszutreten, bei vielen wunderbaren Menschen wahrgenommen habe, für die unsere Gemeinschaft aufgehört hat, in der Liebe und der Wahrheit eingesenkt zu sein. Wenn die Bischöfe wüssten, wie viele es sind und wie schwer es ihnen fällt, in der Kirche zu bleiben... Liebe Priester-Bischöfe, Ihr seid es, die für die polnische Kirche und für die Verkündigung des reinen Evangeliums verantwortlich sind. Wenn Ihr weiter passiv bleibt, werden sich die Kirchen leeren. Scharen von Gläubigen erwarten, dass Ihr, wenn den Medien von Pater Rydzyk nicht der katholische Charakter zurückgegeben werden kann, erklärt, dass diese Medien kein Recht haben, sich als »katholische« zu begreifen. Und dass das Thorner Radio nicht den Namen »Maryja« tragen darf, wenn es Sendungen ausstrahlt, die das Evangelium und damit auch die Muttergottes beleidigen. Ja, ich klage Radio Maryja, Telewizja Trwam und Nasz Dziennik an, dass sie das Christentum und die Kirche in Polen vernichten.

\section{Die monatliche Profanierung}

Da ich mich entschieden habe, wegen der Entchristianisierung Polens Alarm zu schlagen, kann ich die Lektion, die uns seit sieben Jahren auf der Krakowskie Przedmieście-Straße [die historische Nord-Süd-Achse im Zentrum Warschaus, d. Übers.] gegeben wird, nicht übergehen. Es geht natürlich um die monatlichen Smolensk-Gedenktage.

Ich überspringe, was in der Warschauer Kathedrale geschieht: Ich habe früher bereits die skandalösen Worte der dortigen Prediger zitiert und wundere mich fortwährend, dass diese Veranstaltung, halb religiös, halb politisch, fortgesetzt wird. Dieses Mal jedoch will ich auf Dinge aufmerksam machen, die nach dem Verlassen der Kathedrale stattfinden. Ein Umzug setzt sich in Bewegung. An der Spitze wird ein Kreuz getragen. Der Rosenkranz wird gebetet. Unterdessen lesen wir auf Transparenten, dass die Tragödie von Smolensk ein geplantes Verbrechen, dass es »ein Anschlag war«. Gezeigt wird auch ein Bild von Tusk und Putin [im Jahr des Flugzeugunglücks Ministerpräsidenten, d. Übers.] mit der Unterschrift »es ist gelungen«.

Nach der Ankunft vor dem Präsidentenpalast und der Blumenniederlegung folgt der Höhepunkt: die Rede des PiS-Präses, die immer die politischen Gegner als Verräter verunglimpft, immer aufwiegelt und immer von Hass durchdrungen ist: „Unsere Erinnerung will man töten, weil man Angst vor ihr hat. Schuld hat die Regierung von Donald Tusk. Sie haben alles daran gesetzt, dass die Erinnerung stürbe.", "Antoni [Macierewicz, d. Übers.] hat mit seiner Mannschaft ein Wunder vollbracht« (sechster Jahrestag). «Unaufhörlich wurden die Polen belogen, unaufhörlich wurden wir Polen belogen.« »Die Bestattung des Präsidenten und seiner Ehefrau hatte noch nicht stattgefunden, als die 
Angriffe einsetzten [...], die Industrie der Verachtung wurde in Gang gesetzt, das Kreuz wurde attackiert [...] es wurden alle grundlegenden Elemente unserer europäischen Kultur getreten. Es kam zu einer wahren Explosion des Hasses gegenüber der polnischen katholischen Tradition [...]. Das alles geschah mit der Zustimmung oder geradezu auf Empfehlung der Machthaber" (fünfter Jahrestag).

Der Umzug endet mit einem Gebet, das viele Male von Priester Stanisław Małkowski gesprochen wurde (zurzeit wird er von einem anderen Geistlichen vertreten). Neben dem Parteivorsitzenden stehend, hat er einst in Richtung Präsidentenpalast und des damals darin residierenden Bronisław Komorowski Exorzismus gehalten. Und wieder muss man mit lauter Stimme rufen: Das ist nicht das Christentum, das ist nur seine Parodie und die Profanierung des Kreuzes! Feindlichkeit und Hass in religiöser Verpackung sind schlimmer als Heidentum. Warum verstehen so viele Menschen nicht, dass das ansteckend ist?

Viele Gläubige erwarten, dass der Episkopat endlich erklärt, dass die monatlichen Gedenkveranstaltungen keinen religiösen Charakter haben und dass auf ihnen nicht das Kreuz getragen werden darf, und dass die Bischöfe die Geistlichen aufrufen, an den Umzügen nicht teilzunehmen. Ich dagegen klage Jarosław Kaczyński, die Organisatoren und Teilnehmer der Monatsumzüge (auch diejenigen, die in gutem Glauben teilnehmen) an, dass sie das authentische Christentum und die Kirche in Polen zerstören.

\section{Der Hass auf den Straßen}

Auf polnischen Straßen und Plätzen sind bei unterschiedlichen Gelegenheiten immer häufiger merkwürdige Rufe zu hören, zum Beispiel der Reim: »Den roten Mob mal mit der Sichel, mal mit dem Hammer«, oder die Sprüche »Dem Judentum die Macht entreißen«, „Weiße Stärke! Weiße Rasse!«, "Sauberes Blut, nüchterner Verstand«, "Europa wird weiß sein oder unbewohnt«, "Sieg Heil«. Die Politiker scheinen auf die Gruppen, die solche Slogans hinausschreien, mit zugedrücktem Auge zu blicken oder sogar, wie ich vermute, mit einer gewissen Sympathie. Auch viele Geistliche halten die Schreienden für echte Patrioten; auf dem Hellen Berg werden sie mit Ehren empfangen, wie vergangenen Samstag. Einmal sagte ein Unterprior: "Ihr seid die Helden des 21. Jahrhunderts. Als wären Nationalismus, Antisemitismus und Feindseligkeit gegenüber Fremden nicht tödliche Krankheiten die - so lehrt die Geschichte des 20. Jahrhunderts - niemals unterschätzt werden dürfen.

Ich bin kein Gegner des Kontakts zwischen Priestern und solchen Gruppen, im Gegenteil - allerdings muss es ein Kontakt im Geiste des Evangeliums sein. Die Organisatoren der Feierlichkeiten von Fußballfangruppen auf dem Hellen Berg sind sich vielleicht dessen nicht bewusst, dass sich die Teilnahme an der Eucharistiefeier nicht mit aggressivem und hasserfülltem Verhalten vereinbaren lässt, aber die theologisch ausgebildeten Paulinerpatres haben die Pflicht, sie zu belehren und sogar den Ausschluss solchen Verhaltens zu fordern, wenn sie auf dem Hellen Berg empfangen werden wollen. Ähnlich ist es mit dem Marsch der Unabhängigkeit [dieser findet am Nationalfeiertag der Unabhängigkeit am 11. November statt, d. Übers.], der unter dem Motto "Wir wollen Gott« organisiert wurde. Wenn eine Gruppe, Organisation oder Vereinigung als katholisch gelten will, muss sie sich von Feindseligkeit und Hass lossagen. Daher klage ich die Priester an, die Nationalismus und Feindseligkeit tolerieren, und mehr noch die, die sie loben: Wenn Ihr Euch so verhaltet, ruiniert Ihr das Christentum und die Kirche und tragt zum Anstieg der Kräfte bei, die den gesellschaftlichen Frieden bedrohen.

\section{Damit Polen sauber sei}

In den schwärzesten Träumen habe ich nicht vorhergesehen, dass ich Zeuge solcher Ereignisse sein werde. Dass die Regierenden die Bedeutung der Solidarnosśc und der Leistungen Polens nach dem Zusammenbruch des Kommunismus ausstreichen werden, dass sie sagen werden, dass alles, was gut ist, mit ihnen begann, - das wäre noch zu schlucken. Das Problem besteht darin, dass die, die Polen regieren, der Meinung sind, dass auf der anderen Seite nicht Konkurrenten und Gegner stehen, sondern nur Verräter. Deshalb werden sie bespuckt und Verleumdungen ausgedacht. Deshalb heißt es: Sie treten alles, was heilig ist, verachten Polen, sie sind Schurken, dienen fremden Interessen. Gegenwärtig, nachdem mit den Institutionen abgerechnet worden ist, die für Rechtsstaatlichkeit und die zivilgesellschaftlichen Freiheiten stehen, hören wir die Ankündigung, dass die nächste Etappe die Abrechnung eben mit den Verrätern und Feinden sein werde - damit Polen sauber, gerecht und katholisch sein werde. »Damit Polen Polen sei.«

Die einzige Kraft, die in Polen noch über eine gewisse Autorität verfügt, ist der Episkopat. Daher erlaube ich mir zu bitten - übrigens im Namen vieler ähnlich Denkender: Priester-Bischöfe, tretet in die öffentliche Arena ein. Die Stunde hat geschlagen, dass Ihr sehr, sehr gebraucht werdet - von der Kirche, aber auch von Polen.

Übersetzung aus dem Polnischen: Silke Plate

Quellenangabe und Informationen über den Autor finden Sie auf der nächsten Seite. 
Quelle: Ludwik Wiśniewski: Oskarżam. In: Tygodnik Powszechny Nr. 4/2018 (21.01.2018). <www.tygodnikpowszechny. $\mathrm{pl} /$ oskarzam-151647> (abgerufen am 8.02.2017), mit freundlicher Genehmigung.

Pater Ludwik Wiśniewski Ordo Praedicatorum (Jahrgang 1936), Dominikaner. In der Volksrepublik Polen war er Mitorganisator und Unterstützer der Bewegung für die Verteidigung der Menschen- und Bürgerrechte (Ruch Obrony Praw Człowieka i Obywatela - ROPCiO), des Komitees zur Verteidigung der Arbeiter (Komitet Obrony Robotników KOR) und der Bewegung Junges Polen (Ruch Mtodej Polski). Seit 1980 war er Kaplan der Solidarność-Bewegung. Im Jahr 2006 wurde er von Präsident Lech Kaczyński mit dem Kommandeurskreuz des Ordens der Wiedergeburt Polens ausgezeichnet, 2015 von Präsident Bronisław Komorowski mit dem Großkreuz des Ordens der Wiedergeburt Polens.

Das Magazin Tygodnik Powszechny ist ein katholisches Wochenblatt, das bereits in der Volksrepublik Polen den Kreisen der katholischen Intelligenz und der demokratischen Opposition nahe stand. Es vertritt einen liberalen Katholizismus und bietet eine Plattform für den Dialog über Glaubens- und säkulare Fragen.

\section{Erklärung der Polnischen Bischofskonferenz vom 17.01.2018 zum Artikel von Pater Ludwik Wiśniewski unter dem Titel »Ich klage an« (In: Tygodnik Powszechny, 21.01.2018)}

Pater Ludwik Wiśniewski wirft den polnischen Bischöfen in seinem Text "Ich klage an" (Tygodnik Powszechny, 21.01.2018, S. 11-14) vor, dass sie zu aktuellen Angelegenheiten des Lebens der Kirche und der Gesellschaft »schweigen«.

Wie sehen die Tatsachen aus? Dies sind nur einige Beispiele der Aktivitäten der Polnischen Bischofskonferenz aus den vergangenen vier Tagen.

Am Sonntag, den 14. Januar wurde in ganz Polen der 104. Welttag des Migranten und Flüchtlings begangen, an dem das Formular für die »Messe für Flüchtlinge und Vertriebene« eingesetzt wurde, wozu -den liturgischen Vorschriften entsprechend - alle Diözesanbischöfe zugestimmt hatten. Darüber hinaus sensibilisieren die Priester-Bischöfe nicht nur an diesem Sonntag - in den Predigten für die Bedürfnisse der Migranten und Flüchtlinge, indem sie dazu ermutigen, jegliche mögliche Hilfe zu leisten.

Am Montag, den 15. Januar fand im Sekretariat der Polnischen Bischofskonferenz eine Pressekonferenz zum 104. Welttag des Migranten und Flüchtlings in der Katholischen Kirche statt, auf der der Vorsitzende der Polnischen Bischofskonferenz, Erzbischof Stanisław Gądecki, an die Lehre Papst Franziskus' und der Katholischen Kirche zu diesem Thema erinnerte und Bischof Krzysztof Zadarko das Dokument des Dikasteriums für die ganzheitliche Entwicklung des Menschen (Abteilung für Migranten und Flüchtlinge) unter dem Titel „20 Handlungsschwerpunkte zu Migranten und Flüchtlingen« vorstellte.

Am Dienstag, den 16. Januar fand in sozialen Medien eine Debatte über das Thema der Konferenz vom Montag statt.

Am Mittwoch, den 17. Januar gab Erzbischof Stanisław Gądecki, Vorsitzender der Polnischen Bischofskonferenz, ein Dokument über die Gefahr des Nationalismus und die Schönheit des Patriotismus heraus. Es wurde aus Anlass des am 17. Januar 2018 begangenen XXI. Tages des Judaismus veröffentlicht. Am selben Tag richtete Bischof Rafał Markowski, Vorsitzender des Komitees für den Dialog mit dem Judaismus der Polnischen Bischofskonferenz, das Wort, das ein Kommentar und eine Aktualisierung des diesjährigen Mottos des Tages des Judaismus ist: „Friede! Friede den Fernen und den Nahen ( Jes 57, 19).

Der Vorwurf Pater Ludwik Wiśniewskis, dass die "Bischöfe schweigen«, ist also eine grundlose Anschuldigung und ein ungerechter Missbrauch.

Priester Dr. Paweł Rytel-Andrianik

Sprecher der Polnischen Bischofskonferenz

Warschau, den 17.01.2018

Übersetzung aus dem Polnischen: Silke Plate

Quelle: Konferencja Episkopatu Polski [Polnische Bischofskonferenz]: Oświadczenie ws. artykutu o. Ludwika Wiśniewskiego pt. »Oskarzam « (Tygodnik Powszechny, 21.01.2018). <http://episkopat.pl/rzecznik-kep-zarzut-o-wisniewskiegoze-biskupi-milcza-bezpodstawnym-oskarzeniem-i-krzywdzacym-naduzyciem/> (abgerufen am 14.02.2018). 


\section{6. - 19. Februar 2018}

\begin{tabular}{|c|c|}
\hline 06.02 .2018 & $\begin{array}{l}\text { Präsident Andrzej Duda unterzeichnet die umstrittene Gesetzesnovelle über das Institut des Nationalen Geden- } \\
\text { kens, Kommission für die Verfolgung von Verbrechen gegen die Polnische Nation (Instytut Pamięci Narodowej, } \\
\text { Komisja Ścigania Zbrodni przeciwko Narodowi Polskiemu). Gleichzeitig kündigt er an, das Gesetz angesichts } \\
\text { der Kritik aus dem In- und Ausland zur Überprüfung an das Verfassungstribunal weiterzuleiten. Kritik kam u. a. } \\
\text { aus Israel, den USA und der Ukraine. Das Gesetz sieht eine Geldstrafe oder eine Freiheitsstrafe bis zu drei Jahren } \\
\text { vor, wenn der polnischen Nation oder dem polnischen Staat öffentlich und entgegen der Fakten die Verantwor- } \\
\text { tung oder Mitverantwortung für Verbrechen zugeschrieben wird, die von Deutschland in der Zeit des National- } \\
\text { sozialismus begangen wurden, oder für andere Verbrechen gegen die Menschlichkeit, den Frieden sowie Kriegs- } \\
\text { verbrechen. Die gleiche Strafe droht, wenn die Verantwortung der tatsächlichen Täter verringert wird. Die Frei- } \\
\text { heit der Wissenschaften und der Künste und die Freiheit historischer Diskussionen sollen von dem Gesetz nicht } \\
\text { eingeschränkt werden. Kritiker des Gesetzes aus dem In- und Ausland befürchten, dass beispielsweise die Kolla- } \\
\text { boration polnischer Bürger mit der deutschen Besatzungsmacht nicht aufgearbeitet werden könne. }\end{array}$ \\
\hline 07.02.2018 & $\begin{array}{l}\text { In einem Brief an die im Ausland lebenden Polen fordert Senatsmarschall Stanisław Karczewski diese auf, Zeug- } \\
\text { nisse der Verbrechen gegen die Menschlichkeit während des Zweiten Weltkriegs zu sammeln und zu dokumen- } \\
\text { tieren, damit die Erinnerungen über die Zeitzeugengeneration hinaus bewahrt würden. Weiter ruft er dazu auf, } \\
\text { antipolnische Vorkommnisse, die den guten Ruf Polens beschädigten, zu dokumentieren und den Botschaften } \\
\text { und Konsulaten der Republik Polen zu melden sowie in Form von Seminaren, Ausstellungen und in Zusammen- } \\
\text { arbeit mit den Partnern vor Ort etc. aktiv zu sein, um über die historische Wahrheit aufzuklären. Hintergrund ist } \\
\text { die am Vortag unterzeichnete Gesetzesnovelle über das Institut des Nationalen Gedenkens, Kommission für die } \\
\text { Verfolgung von Verbrechen gegen die Polnische Nation (Instytut Pamięci Narodowej, Komisja Ścigania Zbrodni } \\
\text { przeciwko Narodowi Polskiemu), die unter Strafe stellt, wenn der polnischen Nation oder dem polnischen Staat } \\
\text { die Verantwortung oder Mitverantwortung für die von den Nationalsozialisten verübten Verbrechen zugespro- } \\
\text { chen wird. Davon ausgeschlossen sind wissenschaftliche und künstlerische Äußerungen. }\end{array}$ \\
\hline 07.02.2018 & $\begin{array}{l}\text { Ryszard Czarnecki (Recht und Gerechtigkeit/Prawo i Sprawiedliwość - PiS; Fraktion der Europäischen Kon- } \\
\text { servativen und Reformer) wird mit der erforderlichen Zweidrittelmehrheit (447 Stimmen, } 196 \text { Gegenstimmen } \\
\text { und } 30 \text { Enthaltungen) als Vizepräsident des Europäischen Parlaments abgewählt. Der Grund für die Abstim- } \\
\text { mung ist, dass Czarnecki die polnische Abgeordnete Róża Thun von Hohenstein (Bürgerplattform/Platforma } \\
\text { Obywatelska - PO; Fraktion der Europäischen Volkspartei) als Nazi-Kollaborateurin verunglimpfte, nachdem } \\
\text { sie die polnische Regierung in einer Reportage des deutsch-französischen Fernsehsenders »Arte« kritisiert hatte. }\end{array}$ \\
\hline 08.02 & $\begin{array}{l}\text { Die Europäische Kommission teilt mit, dass sie das staatliche Hilfsprogramm für Restrukturierungsmaßnah- } \\
\text { men des Bergbaus in Polen in Höhe von } 5 \text { Mrd. Zloty für die Jahre } 2019 \text { bis } 2023 \text { befürwortet. Es umfasst u. a. } \\
\text { Sozialmaßnahmen für die Bergleute, die vom Abbau der Arbeitsplätze betroffen sind, und Rückbaumaßnah- } \\
\text { men der Bergwerke. }\end{array}$ \\
\hline 08.02 .2018 & $\begin{array}{l}\text { Gesundheitsminister Łukasz Szumowski und Vertreter der Ärzte in der Facharztausbildung zeigen sich zufrie- } \\
\text { den über die Ergebnisse der Verhandlungen über Reformen im Gesundheitswesen. Bis } 2024 \text { sollen die öffentli- } \\
\text { che Finanzierung auf } 6 \% \text { des Bruttoinlandsprodukts steigen und die Gehälter der Ärzte in der Facharztausbil- } \\
\text { dung erhöht werden, wenn sie sich im Anschluss für zwei Jahre auf einer Arbeitsstelle verpflichten. Ministerprä- } \\
\text { sident Mateusz Morawiecki kündigt an, dass in diesem Jahr } 6 \text { Mrd. Zloty zusätzlich für das Gesundheitswesen } \\
\text { bereitgestellt werden. Die Proteste der jungen Ärzte gegen die Situation im Gesundheitswesen hatten im Okto- } \\
\text { ber } 2017 \text { zunächst mit Hungerstreiks begonnen. }\end{array}$ \\
\hline 09.02 .2018 & $\begin{array}{l}\text { Auf einer Pressekonferenz kündigt Ministerpräsident Mateusz Morawiecki die Vereinfachung des Steuersystems } \\
\text { und die Schließung von Steuerschlupflöchern insbesondere bei der Mehrwertsteuer an. Letzteres habe bereits für } \\
\text { das Jahr } 2017 \text { ein Plus von } 30 \text { Mrd. Zloty eingebracht, die für sozialpolitische Zwecke eingesetzt werden. }\end{array}$ \\
\hline 10.02 .2018 & $\begin{array}{l}\text { In ihrem wöchentlichen Video-Podcast sagt Bundeskanzlerin Angela Merkel, mit dem bevorstehenden Antrittsbe- } \\
\text { such des polnischen Ministerpräsidenten Mateusz Morawiecki könne ein neues Kapitel in den deutsch-polnischen } \\
\text { Beziehungen aufgeschlagen werden. Mit Blick auf die in Polen verabschiedete Gesetzesnovelle über das Institut } \\
\text { des Nationalen Gedenkens, Kommission für die Verfolgung von Verbrechen gegen die Polnische Nation (Instytut } \\
\text { Pamięci Narodowej, Komisja Ścigania Zbrodni przeciwko Narodowi Polskiemu) unterstreicht sie, dass die Deut- } \\
\text { schen die Verantwortung für die Verbrechen des Nationalsozialismus, so auch für die Konzentrationslager, tragen. }\end{array}$ \\
\hline
\end{tabular}




\begin{tabular}{|c|c|}
\hline 12.02 .2018 & $\begin{array}{l}\text { Innenminister Joachim Brudziński sagt, der Konflikt mit Israel und den USA im Zusammenhang mit dem } \\
\text { neuen Gesetz über das Institut des Nationalen Gedenkens, Kommission für die Verfolgung von Verbrechen } \\
\text { gegen die Polnische Nation (Instytut Pamięci Narodowej, Komisja Ścigania Zbrodni przeciwko Narodowi Pol- } \\
\text { skiemu) müsse sehr ernst genommen werden, doch werde Polen keine Zugeständnisse bei der Frage der histori- } \\
\text { schen Wahrheit machen. Der in den letzten Jahrzehnten von Polen betriebenen "Politik der Scham« werde nun } \\
\text { eine selbstbewusste Politik auf der Grundlage der Wahrheit entgegengesetzt. In der internationalen Politik müsse } \\
\text { Polen auf gute Beziehungen zu seinen Partnern achten, aber vorrangig sei die Wahrung der Interessen des polni- } \\
\text { schen Staates und seiner Bürger. }\end{array}$ \\
\hline 13.02 .2018 & $\begin{array}{l}\text { Ministerpräsident Mateusz Morawiecki beendet seinen zweitägigen Besuch im Libanon. Nach Gesprächen mit } \\
\text { Ministerpräsident Saad Hariri und Präsident Michel Aoun bekräftigt Morawiecki, dass Polen als souveränes Land } \\
\text { das Recht habe, im Rahmen seiner Migrationspolitik zu bestimmen, wen es aufnehme und wen nicht. Polen } \\
\text { halte es für seine Pflicht, sich in der Flüchtlingshilfe vor Ort zu engagieren, weshalb es technische und logisti- } \\
\text { sche Unterstützung leiste. Weiter erklärt er, dass } 10 \text { Mio. US-Dollar für den Bau von Unterkünften für syrische } \\
\text { Flüchtlinge im Libanon bereitgestellt werden sollen. }\end{array}$ \\
\hline 14.02 & $\begin{array}{l}\text { Der Präsident des französischen Senats, Gerard Larcher, kommt auf Einladung des Senatsmarschalls Stanisław } \\
\text { Karczewski mit einer Delegation nach Warschau. Außer mit Karczewski trifft er sich mit Ministerpräsident } \\
\text { Mateusz Morawiecki, Präsident Andrzej Duda und Sejmmarschall Marek Kuchciński und spricht vor dem Senat. } \\
\text { Thematisiert werden die Vertiefung der bilateralen Kontakte und der Zusammenarbeit im Rahmen des Weima- } \\
\text { rer Dreiecks (Deutschland, Frankreich, Polen) sowie Fragen der europäischen Politik. }\end{array}$ \\
\hline 15.02 & $\begin{array}{l}\text { Innenminister Joachim Brudziński verteidigt das Vorgehen der Polizei, die am Vortag Władysław Frasyniuk, } \\
\text { Oppositioneller in der Zeit der Volksrepublik Polen, in seiner Wohnung in Breslau (Wrocław) frühmorgens fest- } \\
\text { genommen und in Handschellen abgeführt hat. Die Polizei habe sich regelkonform und so, wie gegenüber allen } \\
\text { anderen Bürgern verhalten. Frasyniuk wurde nach einem Verhör wieder auf freien Fuß gesetzt. Ihm wird vorge- } \\
\text { worfen, bei einer Gegendemonstration zum monatlichen Smolensk-Gedenktag in Warschau im Juni } 2017 \text { zwei } \\
\text { Polizisten körperlich angegangen zu haben. Sein Anwalt, Jacek Kondracki, sagt, die Bedingungen für das Anle- } \\
\text { gen der Handschellen seien nicht erfüllt gewesen. Frasyniuk hatte sich trotz Aufforderung nicht der Staatsan- } \\
\text { waltschaft gestellt, da er die Rechtsstaatlichkeit in Polen nicht mehr gewährt sieht. Dies wertet sein Anwalt als } \\
\text { klassisches Beispiel zivilen Ungehorsams. }\end{array}$ \\
\hline 16.02 & $\begin{array}{l}\text { Bei seinem Antrittsbesuch in Berlin thematisieren Ministerpräsident Mateusz Morawiecki und Bundeskanzlerin } \\
\text { Angela Merkel Fragen der bilateralen Zusammenarbeit und der Außen- und Sicherheitspolitik. Merkel betont die } \\
\text { Bedeutung der zivilgesellschaftlichen Zusammenarbeit zwischen beiden Ländern. Morawiecki bekräftigt seine } \\
\text { Kritik an dem Pipelineprojekt Nord Stream } 2 \text { und ruft dazu auf, es im Rahmen der Europäischen Kommission } \\
\text { zu erörtern. Mit Blick auf die Situation in der Ukraine betonen beide, dass es darum gehe, die Souveränität und } \\
\text { territoriale Integrität der Ukraine zu sichern. }\end{array}$ \\
\hline 17.02 & $\begin{array}{l}\text { Am Rande der Münchener Sicherheitskonferenz sagt Ministerpräsident Mateusz Morawiecki im Zusammenhang } \\
\text { mit dem in der vergangenen Woche unterzeichneten, umstrittenen »IPN-Gesetzes«, dass es auch jüdische Täter im } \\
\text { Kontext des Holocaust gegeben habe. Nach dem Gesetz über das Institut des Nationalen Gedenkens, Kommis- } \\
\text { sion für die Verfolgung von Verbrechen gegen die Polnische Nation (Instytut Pamięci Narodowej, Komisja Ści- } \\
\text { gania Zbrodni przeciwko Narodowi Polskiemu) ist es verboten, die polnische Nation oder den Staat für die Ver- } \\
\text { brechen des von den Nationalsozialisten verübten Holocaust verantwortlich oder mitverantwortlich zu machen. } \\
\text { Kritiker befürchten, dass auch das Thema der Kollaboration Einzelner mit der deutschen Besatzungsmacht nicht } \\
\text { mehr uneingeschränkt aufgearbeitet werden kann. }\end{array}$ \\
\hline 18.02 .2018 & $\begin{array}{l}\text { Nach heftiger Kritik vonseiten Israels und jüdischer Organisationen gibt die Regierung eine Erklärung zur Äuße- } \\
\text { rung von Ministerpräsident Mateusz Morawiecki vom Vortag heraus, dass es auch "jüdische Täter« unter den } \\
\text { Tätern der nationalsozialistischen Verbrechen gegeben habe. Morawiecki habe den Holocaust nicht leugnen und } \\
\text { die jüdischen Opfer keiner Verantwortung für den deutschen Völkermord bezichtigen wollen, heißt es in dem } \\
\text { Kommuniqué. Vielmehr solle ehrlich und faktenbasiert über die Verbrechen an den Juden geredet und Versu- } \\
\text { che, die deutschen Täter und die Opfer anderer Nationen gleichzusetzen oder zu vermischen, bekämpft werden. }\end{array}$ \\
\hline 18.02.2018 & $\begin{array}{l}\text { In einem Telefonat mit seinem israelischen Amtskollegen Benjamin Netanjahu bekräftigt Ministerpräsident } \\
\text { Mateusz Morawiecki, dass Polen eine Gleichsetzung der deutschen Täter der Verbrechen während des National- } \\
\text { sozialismus mit den Opfernationen nicht akzeptiere. Allerdings müssten Fälle von Kollaboration aufgearbeitet } \\
\text { werden. Jedoch dürfte aus Einzelfällen nicht die Mitverantwortung einer Nation abgeleitet werden. }\end{array}$ \\
\hline
\end{tabular}




\begin{tabular}{|l|l|}
\hline 18.02.2018 & $\begin{array}{l}\text { Der Verband der Gemeinden Jüdischen Bekenntnisses in der Republik Polen (Związek Gmin Wyznaniowych } \\
\text { Żydowskich w RP - ZGWŻ) bezeichnet es in einer Erklärung als moralische Blindheit, dass Ministerpräsident } \\
\text { Mateusz Morawiecki am Vortag die deutschen Verbrecher des Nationalsozialismus und die polnischen und ukraini- } \\
\text { schen kollaborierenden Täter mit kollaborierenden Juden gleichgestellt habe. Weiter ruft der Verband Morawiecki } \\
\text { und andere Politiker dazu auf, keine unbedachten Äußerungen zu tun, die der historischen Wahrheit widerspre- } \\
\text { chen würden. Dies kompromittiere sie als Person und in ihrem Amt. }\end{array}$ \\
\hline 19.02.2018 & $\begin{array}{l}\text { Michał Dworczyk, Chef der Kanzlei beim Ministerpräsidenten, kündigt die Bildung einer ressortübergreifenden } \\
\text { Arbeitsgruppe zur Bekämpfung der Verbreitung des Faschismus und anderer totalitärer Ideologien an. }\end{array}$ \\
\hline
\end{tabular}

Sie können die gesamte Chronik seit 2007 auch auf <http://www.laender-analysen.de/polen/> unter dem Link »Chronik«lesen. 


\section{ÜBER DIE POLEN-ANALYSEN}

Die Polen-Analysen erscheinen zweimal monatlich als E-Mail-Dienst. Sie werden gemeinsam vom Deutschen PolenInstitut Darmstadt, der Forschungsstelle Osteuropa an der Universität Bremen und der Deutschen Gesellschaft für Osteuropakunde herausgegeben.

Ein Archiv der Polen-Analysen finden Sie im Internet unter <www.laender-analysen.de/polen> Kostenloses Abonnement unter <http://www.deutsches-polen-institut.de/Newsletter/subscribe.php>

Diese Analysen finden Sie online als Lizenzausgabe auf $<$ bpb.de $>$

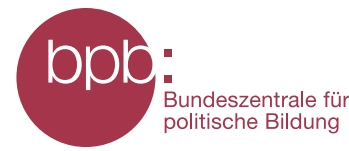

Deutsches Polen-Institut Darmstadt (<www.deutsches-polen-institut.de $>$ )

Das seit 1980 tätige Deutsche Polen-Institut Darmstadt (DPI) ist ein Forschungs-, Informations- und Veranstaltungszentrum für polnische Kultur, Geschichte, Politik, Gesellschaft und die deutsch-polnischen Beziehungen, die sich im Kontext der europäischen Integration entwickeln. Institutionelle Träger des DPI sind das Land Hessen, die Kultusminister der Länder, das Auswärtige Amt und die Wissenschaftsstadt Darmstadt. Einen wesentlichen Beitrag zur Verwirklichung der Institutsziele leisten private Stiftungen. Ziel der Vermittlertätigkeit des DPI ist es, »die zu interessieren, auf die es politisch, wirtschaftlich, gesellschaftlich und kulturell im deutsch-polnischen Verhältnis ankommt« (Leitlinien 1997). Es geht um die Entscheider und Multiplikatoren in Politik, Kultur, Bildung, Verwaltung, Medien und Wirtschaft. Das DPI versteht sich in Kooperation mit den Orten wissenschaftlicher Polen-Kompetenz an deutschen Hochschulen und Forschungsinstituten als verbindendes und vernetzendes Zentrum. Mit der 70.000 Bände zählenden multidisziplinären Fachbibliothek für Polen, die eine einzigartige Sammlung polnischer Belletristik in der Originalsprache und in deutscher Übersetzung umfasst, ist das DPI ein geschätzter Ort der Recherche und des wissenschaftlichen Arbeitens.

Forschungsstelle Osteuropa an der Universität Bremen (<www.forschungsstelle.uni-bremen.de>)

1982 gegründet, widmet sich die Forschungsstelle Osteuropa an der Universität Bremen der interdisziplinären Analyse der Länder Ost- und Ostmitteleuropas in Zeitgeschichte und Gegenwart. Der Forschungsschwerpunkt liegt dabei auf der Rolle von »Dissens und Konsens«, von Opposition und Zivilgesellschaft in ihrem historischen, politischen, gesellschaftlichen und kulturellen Kontext. Die Forschungsstelle besitzt in ihrem Archiv eine einzigartige Sammlung alternativer Kulturgüter und unabhängiger Texte aus den ehemaligen sozialistischen Ländern. Darunter befindet sich auch eine umfangreiche Sammlung des "Zweiten Umlaufs«, die das Schrifttum und Dokumente unabhängiger Initiativen und gesellschaftlicher Gruppen in Polen aus der Zeit von 1976 bis zum Umbruch umfasst. Hinzu kommt eine umfangreiche Bibliothek mit wissenschaftlicher Literatur. Mit Archiv, Bibliothek und zwei wissenschaftlichen Abteilungen ist die Forschungsstelle auch eine Anlaufstelle sowohl für Gastwissenschaftler als auch für die interessierte Öffentlichkeit.

Eine der Hauptaufgaben der Forschungsstelle ist die Information der interessierten Öffentlichkeit. Dazu gehören unter anderem regelmäßige E-Mail-Informationsdienste für Politik, Wirtschaft, Zivilgesellschaft und Medien.

Herausgeber:

Deutsches Polen-Institut, Deutsche Gesellschaft für Osteuropakunde e.V., Forschungsstelle Osteuropa an der Universität Bremen, Leibniz-Institut für Agrarentwicklung in Transformationsökonomien, Leibniz-Institut für Ost- und Südosteuropaforschung, Zentrum für Osteuropa- und internationale Studien (Z0iS) gGmbH

Redaktion:

Prof. Dr. Dieter Bingen (verantwortlich) (Darmstadt) und Silke Plate M.A. (Bremen)

Satz: Matthias Neumann

Wissenschaftlicher Beirat:

Prof. Dr. Stefan Garsztecki, Technische Universität Chemnitz

Prof. Dr. Klaus Ziemer, Kardinal-Stefan-Wyszyński-Universität Warschau

Die Meinungen, die in den Polen-Analysen geäußert werden, geben ausschließlich die Auffassung der Autoren wieder.

Abdruck und sonstige publizistische Nutzung sind nach Rücksprache mit der Redaktion gestattet. Polen-Analysen-Layout: Cengiz Kibaroglu, Matthias Neumann

Alle Ausgaben der Polen-Analysen sind mit Themen- und Autorenindex archiviert unter www.laender-analysen.de

ISSN 1863-9712 @ 2018 by Deutsches Polen-Institut, Deutsche Gesellschaft für Osteuropakunde e.V., Forschungsstelle Osteuropa an der Universität Bremen, Leibniz-Institut für Agrarentwicklung in Transformationsökonomien, Leibniz-Institut für Ost- und Südosteuropaforschung, Zentrum für Osteuropa- und internationale Studien (Z0iS) gGmbH Kontakt: Dr. Andrzej Kaluza, Presse- und Öffentlichkeitsarbeit, Deutsches Polen-Institut, Residenzschloss, Marktplatz 15,

64283 Darmstadt, Tel.: +49/6151/4202-20, Fax: +49/6151/4202-10, E-Mail: polen-analysen@dpi-da.de, Internet: www.laender-analysen.de/polen 

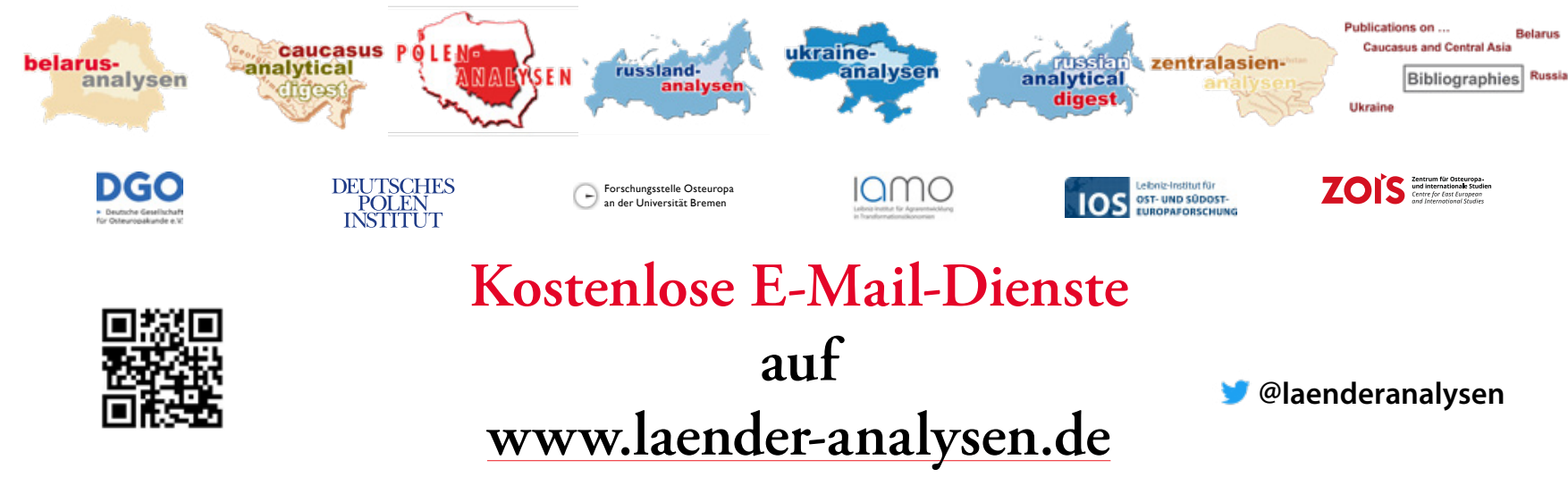

@laenderanalysen

Die Länder-Analysen bieten regelmäßig im kostenlosen Abonnement kompetente Einschätzungen aktueller politischer, wirtschaftlicher, sozialer und kultureller Entwicklungen in Ostmitteleuropa und der GUS. Alle Länder-Analysen verstehen sich als Teil eines gemeinsamen Projektes, das der wissenschaftlich fundierten, allgemeinverständlich formulierten Analyse der Entwicklungen im östlichen Europa, der Offenheit für verschiedene inhaltliche Positionen und der kostenlosen und nicht-kommerziellen Information einer breit verstandenen interessierten Öffentlichkeit verpflichtet ist. Autor/innen sind internationale Fachwissenschaftler/innen und Expert/innen. Die Redaktionen der Länder-Analysen bestehen aus Wissenschaftler/innen mit langjähriger Forschungserfahrung.

Die deutschsprachigen Länder-Analysen werden gemeinsam von der Forschungsstelle Osteuropa an der Universität Bremen, dem Zentrum für Osteuropa- und internationale Studien, der Deutschen Gesellschaft für Osteuropakunde, dem Deutschen Polen-Institut, dem Leibniz-Institut für Agrarentwicklung in Transformationsökonomien und dem Leibniz-Institut für Ost- und Südosteuropaforschung herausgegeben. Die englischsprachigen Länder-Analysen erscheinen in Kooperation der Forschungsstelle Osteuropa mit dem Center for Security Studies (CSS) der ETH Zürich.

Die Länder-Analysen bieten regelmäßig Kurzanalysen zu aktuellen Themen, ergänzt um Grafiken und Tabellen sowie Dokumentationen. Zusätzlich gibt es eine Chronik aktueller Ereignisse. Alle Länder-Analysen sind auch mit Archiv und Indizes online verfügbar unter $<$ www.laender-analysen.de $>$.

\section{Belarus-Analysen}

Erscheinungsweise: zweimonatlich

Abonnement unter: <http://www.laender-analysen.de/belarus/>

\section{Caucasus Analytical Digest}

In englischer Sprache. Erscheinungsweise: monatlich

Abonnement unter: <http://www.css.ethz.ch/en/publications/cad.html>

\section{Polen-Analysen}

Erscheinungsweise: zweimal monatlich

Abonnement unter: <http://www.deutsches-polen-institut.de/newsletter/polen-analysen/>

Auch als App für Android ${ }^{\mathrm{TM}}$ (ab Januar 2016) kostenlos auf Google Play ${ }^{\mathrm{TM}}$.

\section{Russland-Analysen}

Erscheinungsweise: zweiwöchentlich

Abonnement unter: <http://www.laender-analysen.de/russland/>

Auch als App für Android (ab Januar 2016) kostenlos auf Google Play.

Google Play

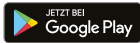

\section{Russian Analytical Digest}

In englischer Sprache. Erscheinungsweise: zweimal monatlich

Abonnement unter: <http://www.css.ethz.ch/en/publications/rad.html>

\section{Ukraine-Analysen}

Erscheinungsweise: zweimal monatlich

Abonnement unter: <http://www.laender-analysen.de/ukraine/>

Auch als App für Android (ab Januar 2016) kostenlos auf Google Play.

\section{Zentralasien-Analysen}

Erscheinungsweise: monatlich

Abonnement unter: <http://www.laender-analysen.de/zentralasien/>

Auch als App für Android (ab Januar 2016) kostenlos auf Google Play.

\section{Bibliographische Dienste}

Die Bibliographien informieren über englisch- und deutschsprachige wissenschaftliche Neuerscheinungen zu Belarus, Russland, Ukraine sowie zu den zentralasiatischen und kaukasischen Staaten. Erfasst werden jeweils die Themenbereiche Politik, Außenpolitik, Wirtschaft und Soziales.

Erscheinungsweise: viermal jährlich

Abonnement unter: $<$ http://www.laender-analysen.de/bibliographies $>$ 